\title{
Educação inclusiva: diferentes configurações, olhares e mundos possíveis
}

\author{
Inclusive education: different configurations, \\ looks and possible worlds
}

Educación inclusiva: diferentes configuraciones, miradas y mundos posibles

ELAine CONTE (Di)

Adilson CRISTIANo HaBowSKi (DD

\section{Resumo}

Nos últimos anos surgiram muitos debates sobre o assunto da inclusão em sala de aula e as dificuldades geradas pela falta de reconhecimento da contribuição pedagógica à formação da pessoa com deficiência associadas a inseguranças, referências de projetos interdisciplinares robustos para contextualizar as desigualdades. Entretanto, no cenário educativo, o que se vê é uma intensa precariedade do ensino público e a omissão dos diversos setores da sociedade que não pensam estratégias articuladoras e integradoras para superar essas problemáticas vitais. Assim, este estudo tem por objetivo realizar uma análise sobre os entraves à atividade do professor em relação à inclusão de crianças com necessidades especiais em sala de aula, a partir de uma revisão de literatura e de um questionário de perguntas abertas, por meio de recursos Google Forms, respondido por cinco professoras que atuam no campo da Educação Inclusiva dos anos iniciais de Educação Básica. Os resultados apontam dificuldades dos educadores nos processos inclusivos à criação de atividades pedagógicas, por inexperiência com o campo na formação acadêmica e ausência de recursos disponíveis nas escolas para dar conta da proposta de inclusão de todos, cujo valor motivacional para o aprender dos estudantes centra-se nas proposições criativas e investigativas do professor. Ficam evidentes

\footnotetext{
a Universidade La Salle (UNILASALLE), Canoas, RS, Brasil. Doutora em Educação, e-mail: elaine.conte@unilasalle.edu.br

b Universidade La Salle (UNILASALLE), Canoas, RS, Brasil. Mestre em Educação, e-mail: adilsonhabowski@hotmail.com
} 
grandes entraves formativos, pois as cinco professoras em atuação, que responderam ao questionário, não possuem formação específica para atuar com crianças deficientes.

Palavras-chave: Inclusão. Professores em atuação. Entraves formativos.

\begin{abstract}
In recent years, there have been many debates on the subject of inclusion in the classroom and as difficulties that result from the lack of recognition of the pedagogical contribution to the training of people with disabilities and as guarantees of the educator to deal with inclusion children. However, in the educational scenario, what you see is an intense precariousness in public education and the omission of several sectors of society that do not think of articulating and integrating strategies to overcome these problems. Thus, this study aims to carry out an analysis on the activities of the educator in relation to the inclusion of children with special needs in the classroom from a literature review and a questionnaire of open questions through resources Google Forms answered for five teachers who worked in the field of Inclusive Education in the Early Years of Basic Education. The results indicate difficulties of educators in the inclusive process, in the preparation of pedagogical activities, or in the planning of academic training and in the absence of resources available in schools to obtain the proposal for inclusion. Great training inputs are evident, as five acting teachers, who answer the questionnaire, do not have specific training to work with children with disabilities.
\end{abstract}

Keywords: Inclusion. Teachers in action. Formative obstacles.

\title{
Resumen
}

En los últimos años, ha habido muchos debates sobre el tema de la inclusión en el aula y como dificultades que resultan de la falta de reconocimiento de la contribución pedagógica a la formación de personas con discapacidad y como garantías del educador para tratar con los niños de inclusión. Sin embargo, en el escenario educativo, lo que se ve es una intensa precariedad en la educación pública y la omisión de varios sectores de la sociedad que no piensan en articular e integrar estrategias para superar estos problemas. Por lo tanto, este estudio tiene como objetivo llevar a cabo un análisis sobre las actividades del educador en relación con la inclusión de niños con necesidades especiales en el aula a partir de una revisión de la literatura y un cuestionario de preguntas abiertas a través de los recursos que Google Forms respondió durante cinco docentes que trabajaron en el campo de la educación inclusiva en los primeros años de la educación básica. Los resultados indican dificultades de los educadores en el proceso inclusivo, en la preparación de actividades pedagógicas o en la planificación de la formación académica y en ausencia de recursos disponibles en las escuelas para obtener la propuesta de inclusión. Son evidentes los excelentes aportes de capacitación, ya que cinco maestros en funciones, que responden el cuestionario, no tienen capacitación específica para trabajar con niños con discapacidades.

Palabras clave: Inserción. Profesores en acción. Obstáculos formativos. 


\section{Introdução}

A Constituição Federal garante a todas as pessoas, com necessidades educativas especiais ou não, o direito à educação de qualidade no ensino regular em instituições públicas (BRASIL, 1988). A inclusão ajuda a combater o preconceito e reconhecer as diferenças como acontecimentos próprios da vida, buscando a valorização das diferenças na ênfase e estímulo às habilidades, capacidades e potencialidades de cada pessoa. Daí advém a nossa preocupação com os professores que atuam com os sujeitos da educação especial, em vista de que possam aprender com a partilha de experiências com os outros, contribuindo assim com outros processos de evolução da educação frente aos desafios da humanidade (MENDES, 2020). Existem muitas discussões sobre como resolver os problemas que envolvem a educação inclusiva, porém, não há medidas efetivas na solução dessas questões e enquanto isso nossas crianças e jovens recebem um ensino compensatório e de baixa qualidade, cerceados por um ensino que apela para as dualidades, divisões e exclusões humanas, preparados para atender um mundo cada vez mais competitivo, desigual e de princípios opostos.

Cabe destacar que as escolas, em sua maioria, também passam por dificuldades financeiras, estruturais e até mesmo de gestão da comunicação. Não oferecem condições adequadas para receber os estudantes, negligenciando formas dignas de ensino, seja pelo excesso de estudantes por turma, que inviabiliza as possibilidades de um acompanhamento individualizado, ou pelo excesso de trabalho (cansaço) do educador em dar conta de todos no processo de ensino, comprometendo o desenvolvimento global dos estudantes que buscam (re)conhecimento e melhoria da qualidade de vida. Diante das condições da educação brasileira, fica difícil a inclusão de crianças com necessidades especiais na educação regular sem o devido suporte especializado que ofereça aos educadores orientações e assistência (BUENO, 1993).

A educação inclusiva é aquela que oferece um ensino (re)contextualizado às diferenças e às necessidades de cada estudante e não deve ser vista como uma ação pedagógica isolada, compartimentalizada, mas como parte do sistema regular de ensino, ou seja, sendo coordenada por ações dialógicas e projetos interdisciplinares ${ }^{1}$.

\footnotetext{
${ }^{1} \mathrm{~A}$ atitude interdisciplinar implica o diálogo com outras áreas e fontes do saber. Hilton Japiassu (2016, p. 3) afirma que o grande desafio "[...] neste início do século e milênio é a contradição 
Para que ocorram processos de inclusão escolares e depois no mercado de trabalho são necessários espaços à expressão do diálogo interdisciplinar e à constituição humana em todas as potencialidades, de forma democratizada, aberta à expressão (multi)cultural, assegurando, por extensão, a pluralidade e a diversidade no campo pedagógico.

\begin{abstract}
Pensar o múltiplo e o móvel é o desafio, ser capaz de lidar ao mesmo tempo com diversas interpretações e perspectivas. Não mais pensar de modo sucessivo, mas simultâneo, compor em vez de excluir, e retomar a difícil complexidade que é viver, pensar, criar, conhecer, querer, sentir... Todas as coisas se relacionam, não há nada realmente isolado, todo gesto produz desdobramentos incalculáveis; um saber, uma escola, uma pessoa não existem sem um contexto: talvez esse seja o aprendizado social, a maturidade política de que precisamos (MOSÉ, 2013, p. 14).
\end{abstract}

Tudo indica que "pensar em políticas públicas de inclusão de pessoas com deficiência implica fazer uma leitura reflexiva cuidadosa dos diversos fatores sóciopolítico-econômicos e culturais que norteiam e limitam a atuação dessa política" (FRANÇA; PAGLIUCA; BAPTISTA, 2008, p. 116). A razão disso fica evidenciada no fato de que o processo de inclusão educacional também repercute na inclusão sociocultural e na qualificação para o mercado de trabalho. Com a economia em crise e a desigualdade socioeconômica aumentando em nosso país, fala-se muito na necessidade de inovação da educação, mas, quanto mais difíceis as condições de trabalho do professor, mais predominam os esforços para sobreviver, esvaziando o sentido da inovação (CHARLOT, 2014). Bernard Charlot (2014, p. 1) comenta sobre a dinâmica extenuante dessa profissão, que trabalha com o reconhecimento da condição humana indeterminada, com a convergência de conhecimentos e com fontes empíricas diferenciadas:

Ser Professor (a) sempre é um desafio, sejam quais forem a sociedade e o contexto. [...] As formas como se desenrola esse desafio e se vivem essas contradições são relacionadas com o contexto social e cultural. Estamos vivendo, na sociedade contemporânea, profundas mudanças na relação com o desejo e na relação com o saber. Além disso, essa sociedade está pedindo ao Professor cada vez mais coisas, muitas vezes vagas e até contraditórias. Por exemplo, o Professor deve ser construtivista em uma escola organizada para práticas tradicionais e com alunos que querem, antes de tudo, passar de ano. O que fazer? Chorar? Ou considerar que o trabalho do Professor, na sociedade

entre, de um lado, os problemas cada vez mais globais, interdependentes e planetários, do outro, a persistência de um modo de conhecimento ainda privilegiando os saberes fragmentados, parcelados e compartimentados". 
contemporânea, é, ao mesmo tempo, impossível de ser feito e mais importante do que nunca. $\mathrm{E}$, talvez, mais interessante...

Sem sombra de dúvidas, torna-se indispensável o debate sobre a formação de professores no mundo digital, tendo em vista que ainda lutamos por investimento, recursos e reconhecimento no mundo do trabalho para garantir a condição humana de sujeitos de direitos, inconclusos, diferentes, imperfeitos e com (des)igualdades de chances para interagir na reciprocidade à evolução social (GLAT; FERNANDES, 2005). Assim como o ato de educar na perspectiva inclusiva é complexo, a formação de professores também merece ênfase quando se aborda a inclusão no contexto sóciohistórico da exclusão, pois implica uma sensibilidade para com o outro, o estranho e suas diferenças (CARVALHO; HABOWSKI; CONTE, 2019). Além disso, os ritmos alucinantes a que são submetidos os professores no trabalho cotidiano precisam ser tematizados, visto que geram insegurança e ansiedade, somados ao aprofundamento das desigualdades sociais, dos transtornos e síndromes dos estudantes, cada vez mais comuns nas escolas.

Acredita-se que a formação docente e a busca pela qualidade do ensino para crianças com necessidades educativas especiais envolvem, pelo menos, dois tipos de formação profissional: a primeira é a dos professores do ensino regular que conte com 0 conhecimento mínimo exigido, uma vez que há a possibilidade de lidarem com estudantes com necessidades educativas especiais (BUENO, 1993); a segunda é a de professores especialistas que possam atender diretamente os sujeitos com tais necessidades e/ou auxiliar o professor do ensino regular em sala de aula (BUENO, 1993). (OLIVEIRA et al., 2012, p. 3).

A fim de que os dois tipos de formação profissional fiquem melhor elucidados, cabe destacar a necessidade de ofertar, desde o campo teórico-interpretativo da formação universitária, uma espécie de formação inclusiva na prática, ou seja, que durante a graduação os futuros professores entrem em contato com experiências de poder aprender com todas as crianças e jovens (MENDES, 2020), bem como desenvolvam projetos conjuntos para o campo da educação inclusiva de conhecimentos interdisciplinares "que os auxiliem a se aproximarem das pessoas com deficiência, no sentido de integrarem com elas, obtendo assim subsídios para atuarem pedagogicamente" (LIMA, 2002, p. 122).

A lei da inclusão prevê que todos os cursos de formação de professores, do magistério à licenciatura, tenham acesso a exemplos de práticas pedagógicas 
verdadeiramente inclusivas, no sentido de capacitar os professores a interagir com a diversidade de características humanas, com pessoas diferentes em suas salas de aula, com e sem necessidades educacionais especiais, dentre os quais os estudantes deficientes (BRASIL, 2015). Diante da obrigatoriedade de inclusão nas escolas das crianças com necessidades especiais, indagamos: como ir além da simples integração assistencial na escola, para que sejam, de fato, incluídas? Será que os professores na práxis estão realmente conseguindo garantir o direito à educação inclusiva de todos? Portanto, o presente estudo tem por objetivo refletir sobre a perspectiva da formação de professores frente à necessidade legal de atuação pedagógica na educação inclusiva.

De acordo com nossa experiência, os estudantes que compõem qualquer grupo ou turma são inevitavelmente diferentes entre si e desenvolvem-se de maneira distinta. Estratégias pedagógicas e métodos de avaliação que pressupõem homogeneidade no processo de ensino e aprendizagem excluem aqueles que não atingem padrões inflexíveis de desempenho. Nesse sentido, acreditamos que os educadores terão maior chance de cumprir seu papel a partir do momento em que perceberem e explorarem as singularidades de cada estudante. Incluir, portanto, não significa normalizar, tentar encaixar alguém considerado diferente em um modelo tal qual ele se apresenta. Adaptações superficiais são efêmeras e não dão conta do recado. Para nós, incluir corresponde a singularizar, assumir como ponto de partida que todo aluno é único quanto a sua história e suas potencialidades. Diante desse dado, a missão do educador é planejar, caso a caso, práticas que reconheçam tais diferenças, mesmo que tenha consciência, como a maioria de nós, de suas limitações em identificá-las. (MENDES, 2020, p. 28).

Este estudo foi construído, inicialmente, a partir de uma pesquisa teóricointerpretativa, uma vez que buscou investigar como ocorre a formação dos professores para avançar no campo da educação inclusiva, dando ênfase à leitura dos desafios teórico-práticos, à tematização e à criticidade da situação vigente (MINAYO, 1995). A produção dos dados será elaborada com a revisão e utilização de livros e artigos da área, além de uma aproximação ao campo empírico através da aplicação de questionário semiestruturado, por meio de recursos Google Forms, a professores dos anos iniciais de Educação Básica. O público-alvo da pesquisa foram cinco professoras dos anos iniciais que atuam na área ou que estão matriculadas no curso de Pedagogia. A participação foi voluntária e por adesão ou interesse nesse campo de conhecimento, e o critério de inclusão destes professores é pelo fato de que atuam com alunos com deficiência em sala de aula, alguns mais recentes e outros há mais de dois anos. A pesquisa escolhida, portanto, discorre sobre uma situação real com a produção de dados, além de manter um contato direto do pesquisador com o público-alvo, tendo 
em vista a preocupação em retratar as perspectivas dos participantes. A preocupação desse trabalho implica discutir e dar voz aos professores que também desejam qualificar os processos de ensino e construção do conhecimento com as múltiplas deficiências presentes nas práticas concretas e expressas nas propostas e diretrizes para a formação, a fim de dar expressão aos sujeitos da práxis pedagógica.

\section{A educação inclusiva em questão}

Podemos constatar inúmeros relatos de exclusão de pessoas com deficiências, cujas barreiras seletistas iniciavam com o tratamento depreciativo e a segregação com relação às expectativas individuais de aprendizagem, geralmente chamados de anormais, aleijados, débil mental, mancos, cegos, mongoloides, etc. (CARVALHO; HABOWSKI; CONTE, 2019). A exclusão de sujeitos com deficiências também era pautada no reconhecimento desses como beneficiários passivos de apoio, tendo por base os sentimentos de piedade ou asfixia social, observando a formação de professores como objeto de preocupação (LAMICHHANE; SAWADA, 2013). Isso para mostrar que, no Brasil, a pessoa com deficiência foi maltratada por séculos, sendo relegada à categoria dos miseráveis e impactada pela exclusão do convívio social e educacional, incluindo, recentemente, um falso reconhecimento por laudos como resposta a questionamentos e angústias de uma inclusão parcial da escola.

Em grande medida essa imprecisão tem impactado na perspectiva de escolarização destes sujeitos que continuam sendo caracterizados a partir de pressupostos biológicos focalizados nas características do laudo, em detrimento de concepções sociais e de direitos [perspectiva educativa e processual de que a inteligência se aprende e se constrói na interação com o outro] (BUENO, 2009; BRIDI, 2011; CARNEIRO, 2017; PLETSCH; PAIVA, 2018). (CAETANO; PLETSCH, 2019, p. 403).

Contudo, as transformações do século XX possibilitaram novas proposições investigativas na área médica, "trazendo questionamentos sobre os meios necessários às pessoas com deficiências para terem uma vida mais digna, com relação ao direito de participar das esferas social e educacional" (CARVALHO; HABOWSKI; CONTE, 2019, p. 158). Avanços vêm, por exemplo, ao reconhecer os direitos das pessoas com deficiência em construções políticas como o Art. 201 da Constituição Federal Brasileira de 1988 (BRASIL, 1988), associadas a novas legislações a respeito 
do tema, como a Lei $\mathrm{n}^{\circ} 7.853 / 89$, a chamada Lei de Cotas, que instituiu a reserva de mercado de trabalho com a criação de normas e condutas para acessibilidade, para a integração da pessoa com deficiência (BRASIL, 1999b).

Neste contexto, Araujo et al. (2010, p. 407) fazem uma retrospectiva histórica sobre as normativas curriculares que orientaram as instituições formadoras de professores, para dar conta dos conteúdos e das especificidades dos alunos com deficiência. Apontam os Parâmetros Curriculares Nacionais: Adaptações Curriculares (BRASIL, 1998) como um marco para a criação de estratégias "para viabilizar um modelo de escola inclusiva, [além da] criação de programas de formação e capacitação dos professores das classes regulares para transformar sua prática educativa" (ARAUJO et al., 2010, p. 407). Além disso, foram instituídas as Diretrizes Nacionais para a Educação Especial na Educação Básica (BRASIL, 2001a), que, juntamente com as Diretrizes Curriculares Nacionais para a Formação de Docentes da Educação Infantil e dos Anos Iniciais do Ensino Fundamental, em nivel médio, na modalidade Normal (BRASIL, 1999a), as Diretrizes Curriculares Nacionais para a Formação de Professores da Educação Básica, em nível superior, curso de licenciatura de graduação plena (BRASIL, 2001b) e as Diretrizes Curriculares Nacionais para o Curso de Graduação em Pedagogia, licenciatura (BRASIL, 2006), orientam a organização curricular das instituições formadoras dos professores no Brasil (ARAUJO et al., 2010).

A inclusão escolar é sinônimo de (re)conhecimento do outro e valorização das diferenças humanas enquanto condição ontológica do ser, uma realidade que vem ganhando força pelo papel fundamental nas apropriações do convívio social das últimas décadas e está inserida no conjunto cultural das diversas modalidades educacionais. Apesar de algumas instituições de ensino contarem com o apoio de profissionais especializados para apoiar o professor no trabalho com as diferenças por estratégias diferenciadas, estamos longe de avançar nas práticas que têm por base o desenho universal para a aprendizagem — DUA (BOCK; GESSER; NUERNBERG, 2019), ou que fomentem projetos educativos interdisciplinares subjacentes à educação inclusiva. O DUA acolhe as expectativas dos participantes e considera a eliminação das barreiras por ações interdisciplinares que emergem das necessidades próprias e contextos, tendo em vista que a "participação de pessoas com características diversificadas para aprendizagem é fundamental para a construção de ambientes mais 
inclusivos, desvelando necessidades de adequações em objetivos, materiais, estratégias, avaliações e organização" dos espaços de aprendizagem (BOCK; GESSER; NUERNBERG, 2019, p. 1-2).

O eixo das ações que conduzem à inclusão tem por base um pensamento que reconhece e valoriza a diversidade na vida em sociedade. Nesse sentido, a ideia de inclusão visa assegurar o acesso das pessoasa todas as possibilidades de convívio social, enquanto sujeitos de possibilidades, integrando e contextualizando as peculiaridades de cada sujeito e grupo social. Observa-se que nos inúmeros fóruns sobre educação inclusiva se têm incrementado ações e políticas referentes à proteção das formas de interação que garantem o exercício pleno e equitativo de todos, com ou sem deficiência. Por isso, adotam-se políticas públicas de promoção e respeito à dignidade da pessoa humana em situação de risco ou vulnerabilidade. (CARVALHO; HABOWSKI; CONTE, 2019, p. 158).

Como já referimos anteriormente, a Constituição Federal brasileira tem uma visão de criança como pessoa de direitos à vida, à liberdade, à igualdade, à segurança e à propriedade, pois, constrói sua identidade pessoal e coletiva pelas interações, relações e práticas cotidianas, brincando, aprendendo, experimentando, questionando e construindo sentidos sobre a natureza, a sociedade e produzindo cultura (BRASIL, 1998). No entanto, Eduardo Galeano (1999, p. 11) diz:

Dia a dia nega-se às crianças o direito de serem crianças. Os fatos, que zombam desse direito, ostentam seus ensinamentos na vida cotidiana. O mundo trata os meninos ricos como se fossem dinheiro, para que se acostumem a atuar como o dinheiro atua. $O$ mundo trata os meninos pobres como se fossem lixo, para que se transformem em lixo. E os do meio, os que não são ricos nem pobres, conserva-os atados à mesa do televisor, para que aceitem desde cedo como destino, a vida prisioneira. Muita magia e muita sorte têm as crianças que conseguem ser crianças.

Os direitos fundamentais da criança e do adolescente foram regulamentados para explicitar a ideia de socialização da criança cidadã, "que significa entendê-las como sujeitos de direitos, que merecem proteção integral, porque se encontram em condições especiais de desenvolvimento" (FERREIRA, 2006, p. 38).

A Política Nacional de Educação promove “o acesso, a participação e a aprendizagem dos alunos com deficiência, transtornos globais do desenvolvimento e altas habilidades/superdotação nas escolas regulares, orientando os sistemas de ensino para promover respostas às necessidades educacionais especiais" (BRASIL, 2007, p. 65). Além disso, busca incluir e adaptar formas de ação, segundo os preceitos teóricos ou técnico-científicos: 
a) Transversalidade da educação especial desde a educação infantil até a educação superior; b) Atendimento educacional especializado; c) Continuidade da escolarização nos níveis mais elevados do ensino; d) Formação de professores para o atendimento educacional especializado e demais profissionais da educação para a inclusão escolar; e) Participação da família e da comunidade; f) Acessibilidade urbanística, arquitetônica, nos mobiliários e equipamentos, nos transportes, na comunicação e informação; e g) Articulação intersetorial na implementação das políticas públicas (BRASIL, 2007, p. 67).

Nesse contexto, retomamos a questão acerca das necessidades pungentes em torno dos fenômenos educativos e socioculturais no mundo à criação de modos de existência outros, afinal de contas, "como incluir em uma sala de aula com 30 a 40 crianças as singularidades e as diferenças daqueles que não conseguem se comunicar ou se mover, sem segregar? A atenção às múltiplas deficiências na escola precisa ser ampliada com novas leituras e interações, principalmente pelos professores" (CARVALHO; HABOWSKI; CONTE, 2019, p. 159-160).

Os conceitos de integração e inclusão ainda geram muitas polêmicas no meio acadêmico, principalmente pelo fato de alguns autores os contraporem e outros acreditarem que se complementam. A confusão entre os conceitos se faz quando atribuem à educação inclusiva o processo de inserir o aluno com necessidade educacional especial no espaço de aula regular, tendo que para isso adaptar-se. Basta inseri-lo. Isso cria a ilusão que estão em correspondência com preceitos inclusivos. (OLIVEIRA et al., 2012, p. 6).

O debate sobre a educação inclusiva pode recair em conceitos simplificadores, normativos, conformistas e adaptativos à instrumentalidade do ensino quando dispensa a condição humana de aprender a desenvolver-se por laços interpessoais, na perspectiva da educabilidade, do ousar transformar-se pelas experiências com o mundo, da interação social com o outro pela linguagem ou por estimulações no contato com as diferenças. Nota-se que a inclusão sob o paradigma de educação para todos "surge como um novo olhar sobre as questões educacionais. Não mais o estudante tem que apresentar uma prontidão para estar na escola, mas a própria escola é chamada a ver que ela pode causar algum empecilho ou dificuldade de integração das diferenças de aprendizagem" (CARVALHO; NAUJORKS, 2006, p. 2). Em face da tentativa de diminuir as barreiras e limitações do processo de inclusão no cotidiano da educação básica surgem tendências que perdem sua potência no processo de escolarização.

Nessa denúncia desenhada se percebe claramente o quanto os dispositivos da escola ainda se prestam a selecionar, a classificar e a hierarquizar seus atores, sobretudo, os alunos, se apresentando como mecanismos, mais do que de poder, de dominação ou [...] 
de opressão. Nota-se ainda [...] os impasses na escola ao ponto de ser possível vislumbrar: de um lado, uma estratégia comum as de que muitas pessoas que são colocadas à margem se utilizam e, de outro, o ato de conviver com os efeitos de sua própria deficiência, revelando todo um processo de superação das dificuldades e dos limites vivenciados singularmente pelos deficientes, assim como a dos demais, inclusive, daqueles que falam em inclusão, sem desejar ouvir seu clamor sobre como gostaria de ser tratado: como um a mais (PAGNI, 2017, p. 162).

Essa dimensão a neutralizar, desencorajar ou opacificar as vozes discordantes faz parte dos desafios formativos para fazer avançar as práticas inclusivas, indo além de um conjunto de medidas impositivas num plano mais ideológico, que têm sido conjecturadas em produções políticas, sobretudo pela rede pública de ensino.

[...] necessidades educacionais especiais na rede regular de ensino não consiste apenas na permanência física desses alunos junto aos demais educandos, mas representa a ousadia de rever concepções e paradigmas, bem como desenvolver o potencial dessas pessoas, respeitando suas diferenças e atendendo suas deficiências. $O$ respeito e a valorização da diversidade dos alunos exige que a escola defina sua responsabilidade no estabelecimento de relações que possibilitem a criação de espaços inclusivos, bem como procure superar a produção, pela própria escola, de deficiências especiais (BRASIL, 2001a, p. 28).

Sabemos que são muitos os conflitos e contradições que têm sido enfrentados na concretização dos ideais de inclusão escolar nesse campo que requer a participação em grupos de estudantes e o trabalho interdisciplinar de professores, visto que precisaríamos aprender com as diferenças e não com as desigualdades (GIMENEZ, 2006). Os desafios da inclusão, em termos de acessibilidade sociocultural ou vulnerabilidade para os que possuem algum tipo de deficiência, são ilustrados nas charges em circulação nas redes sociais, indicando uma perspectiva mais operacional e enquadrada do que experimentamos na atualidade.

Figura 1 - Charges sobre os desafios da inclusão 


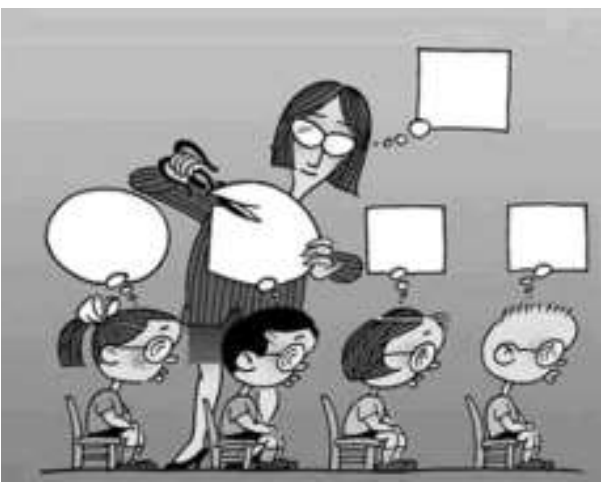

(a)

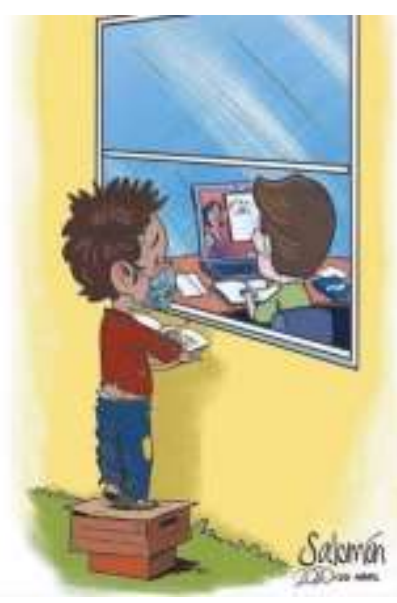

(c)

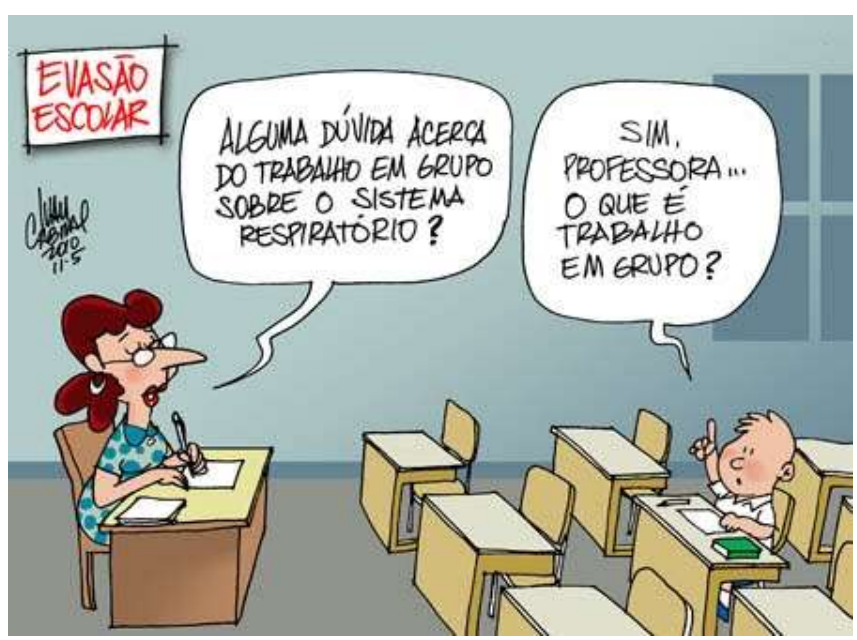

(b)

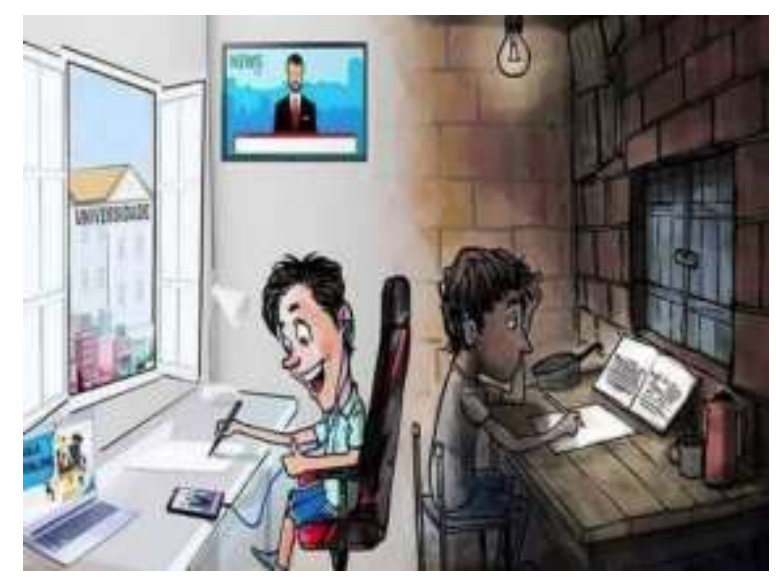

(d)

Fonte: (a) Marcelo Sabbatinni (2021)2; (b) Cabral (11 de maio de 2010)3 ${ }^{3}$, (c) Salomón (abril de 2020); (d) SANTOS (2021).

Apesar dos avanços em termos de políticas governamentais para incentivar o processo de educação inclusiva dos estudantes sem e com deficiências, por distintas formas de integração física, social, funcional e societal nas possibilidades de tecnologias sociais (CARVALHO, 2000), há, conforme ilustramos nas formas de educação em

\footnotetext{
2 Disponível em: http://www.marcelo.sabbatini.com/educacao-em-charges-2/ Acesso em: 17 ago. 2021.

3 Disponível em: http://nepfhe-educacaoeviolencia.blogspot.com/2012/01/brasil-dados-docenso-escolar-do-mec.html Acesso em: 17 ago. 2021.

4 Disponível em: https://petletras.paginas.ufsc.br/2020/05/28/as-tecnologias-o-ensino-adistancia-e-seus-desafios/ Acesso em: 17 ago. 2021.
} 
charges, lacunas na garantia de condições mínimas de trabalho do professor nas escolas para atuarem com a inclusão de todos, especialmente no sentido de apoiar projetos interdisciplinares robustos que auxiliem os estudantes com deficiência (LIMA, 2002). Ainda assim, para que ocorra uma educação inclusiva mais efetiva, o importante é capacitar não só o professor, mas toda a comunidade escolar, "respeitando os princípios dos pilares éticos, sociais e normativos de cada realidade. Sendo necessário que a escola encontre alternativas práticas, construídas e dialogadas para incluir efetivamente” (GONÇALVES; GONÇALVES; FIRME, 2016, p. 866). Enfim, compartilhando ideias e projetos no coletivo torna-se viável promover o avanço de aprendizagens sociais e interdisciplinares via DUA, no sentido do estabelecimento de escolas realmente inclusivas.

A busca por maior participação e acesso ao conhecimento pelos distintos sujeitos da educação não é uma preocupação exclusiva do campo de estudos sobre deficiência, nem, tampouco, algo a ser investigado numa única etapa, nível ou modalidade de ensino. Estudos para consolidar práticas inclusivas, pautadas no modelo social da deficiência, ainda são escassos e, portanto, com diferentes necessidades e caminhos para investigação. (BOCK; GESSER; NUERNBERG, 2019, p. 20).

Os dados deste estudo mostraram ainda que "o DUA, enquanto fio condutor de práticas pedagógicas, mostrou-se potente para o enfrentamento do capacitismo" BOCK; GESSER; NUERNBERG, 2019, p. 20). Dessa forma, apostar no trabalho interdisciplinar entre professores desperta novos olhares pedagógicos para além da capacitação por cursos (MIT'TLER, 2003), uma vez que influencia os sentimentos dos professores em relação à educação inclusiva interseccional gerando mudança pela cultura cooperativa, referenciando, assim, a diversidade das práticas e estratégias profissionais, assim como os diferentes ritmos e estilos de aprendizagem dos estudantes. Se a preocupação com a formação de professores voltada para ações do trabalho interdisciplinar e interseccional à educação inclusiva é recente, ao mesmo tempo, é necessário encorajar os futuros professores a aproximar os propósitos do DUA a processos de formação permanente para ressignificar e reconstruir as práticas educacionais à elaboração conjunta de materiais e atividades educativas e flexíveis para o aprendizado de todos, reorientando os desafios teóricos e práticos de outros olhares profissionais (SIEMS, 2008). "Costa (2013) defende que com a perda de consistência dos discursos e falta de segurança no ato de educar com as diferenças e a pluralidade 
cultural, há um apelo emotivo e afetivo para que a educação inclusiva seja um ato de amor” (OLIVEIRA et al., 2012, p. 9). E isso faz com que segregação e exclusão sejam representadas e revestidas de amor, dedicação e cuidado comuns a modelos antigos, ou seja, sem uma preocupação com a estimulação à curiosidade e à leitura do mundo dos educandos. Sem sombra de dúvidas, há muito a se evoluir em termos de qualificação profissional, de modo que a ampliação e continuidade dos cursos de capacitação são indispensáveis para a formação de professores — atores que pensam e projetam os processos de inclusão socioeducacional. Investimentos em tecnologias e em materiais didáticos não devem ser descartados. Nesse contexto, o trabalho de inclusão educacional exige uma nova visão sobre o fazer pedagógico, resistindo às barreiras maniqueístas, dualistas e seletivas de aprendizagem, uma vez que somos sujeitos de possibilidades mesmo tendo algumas limitações (de conhecimentos ou de movimentos) ou necessidades especiais (físicas, cognitivas, comportamentais, entre outras).

É de suma importância que o meio social acolha e envolva o educando ao invés de decretar sua adaptação forçada à sociedade. Já sabemos que as competências exigidas para a inclusão do outro, que hoje recaem sobre o professor, não são algo estático, mas interdependem de estímulos pessoais e profissionais, pois competências são construídas no percurso formativo ao movimentar as disposições humanas, sejam elas cognitivas, objetivas ou sociais de conveniência, englobando diferentes situações e experiências pedagógicas (PERRENOUD, 2000; GONÇALVES; GONÇALVES; FIRME, 2016). De acordo com Sverdlick (2019, p. 1), há, ainda, disputas nos campos das práticas políticas e lutas de poder discursivo sobre os "significados que o direito à educação e à inclusão educacional tiveram em diferentes modelos ou propostas educacionais ao longo do tempo e sua configuração particular no presente". Agregase a essa perspectiva a pesquisa de Mendes (2019), que discute as políticas de Educação Inclusiva, tendo em vista o futuro das instituições especializadas no Brasil. A autora conclui que as instituições especializadas "deveriam ser reconfiguradas, não como centros de apoio, mas como escolas especiais propriamente ditas, fazendo parte de uma rede diversificada de serviços articulados para apoiar as necessidades" dos estudantes da Educação Especial (MENDES, 2019, p. 2). 
Conforme vimos até aqui, são muitos os entraves na formação de professores para o exercício do trabalho com estudantes deficientes na escola regular, que exclui muitas crianças do acesso ao conhecimento. Michels (2017, p. 23) aponta que "a perspectiva histórica assume papel relevante nesta discussão, uma vez que é nela que encontraremos o movimento, a mudança, a ruptura, a continuidade, as permanências e as transformações". Um professor tem papel fundamental na vida do seu estudante, por isso os cursos de Pedagogia precisam criar incentivos para formar não apenas especialistas de um campo, mas capazes de enfrentar o processo pedagógico em que trabalham, tendo em vista os problemas mais significativos nas formas de aprender e ensinar, bem como a necessidade de ofertar um tratamento especial e diferenciado para todos, no sentido de contemplar a pluralidade humana e as novas realidades escolares. É nesse contexto que analisamos, no tópico a seguir, as visões, os sentidos e as palavras dos professores que atuam nesse campo, como forma de reflexão complementar acerca das práticas relacionadas à inclusão educacional.

\section{Entraves na formação e qualificação de professores}

Apesar do caráter individualista e solitário como se configura o papel do professor nas diretrizes legais de inclusão educativa, defendemos que os professores precisam ser, antes de tudo, pesquisadores do processo de construção da prática pedagógica, agentes dos processos de construção do conhecimento, em busca de formação permanente e colaborativa em sua área de atuação, para que projetem juntos correções necessárias aos equívocos históricos ainda vigentes. Nas dinâmicas atuais de retrocesso e regressão educativa, torna-se necessário pensar o direito à educação como incentivadora e transformadora da cultura em sociedade e da vida dos estudantes, garantindo assim o incentivo para continuar pensando alternativas viáveis às práticas pedagógicas. Daí que realizamos essa pesquisa em uma escola de rede pública de ensino fundamental do município de Canoas/RS.

Elaboramos um questionário de perguntas abertas que foi respondido por cinco professoras ${ }^{5}$ que atuam no campo da educação inclusiva. As questões

\footnotetext{
5 Neste texto, o nome das professoras foi modificado para respeitar o anonimato das participantes.
} 
orientadoras foram as seguintes: (1) Sente-se preparado(a) para atuar no atendimento ao estudante com deficiência? Quais os conflitos que percebe para a produção do conhecimento em relação à inclusão das diferenças e deficiências na escola?; (2) A informação que você tem sobre a inclusão de alunos com deficiência na escola é (marque X na resposta adequada): Nula, Insuficiente, Suficiente/Regular, Boa, Excelente; (3) Quantos alunos deficientes existem na escola? Quais os tipos de deficiência?; (4) Como é feita a integração de alunos com necessidades especiais? Há algum tipo de apoio ao professor durante as aulas? Qual?; (5) Há participação da família do deficiente dentro da escola? Como?; (6) Quais as principais dificuldades enfrentadas pelos professores quando se trata da inclusão?; (7) De que forma é possível capacitar o professor e a escola para fazer a inclusão de estudantes com múltiplas deficiências?; (8) Você acredita na prática escolar inclusiva? O professor pode assumir o papel central no sentido de promover e estimular uma postura inclusiva entre seus estudantes, como?

Em conversas iniciais feitas com as cinco professoras, de forma individual, identificamos que as participantes são do sexo feminino, três delas têm formação em Pedagogia e duas em Magistério e estão trabalhando na área de inclusão escolar por mais de três (3) anos. Também, as professoras possuem uma faixa etária que varia entre vinte (20) e trinta e oito (38) anos de idade. Dito isso, elencamos, na forma de relato, algumas respostas das professoras, que trazem perspectivas e um olhar sensível à questão dos entraves para a formação de professores e seus desdobramentos à educação inclusiva.

A professora Franciele atua no Ensino Fundamental e Educação Infantil, possui vinte e nove (29) anos e tem a especialidade em Estudos Culturais. Na primeira pergunta (1), Franciele diz que se sente "parcialmente preparada" para atuar no atendimento ao estudante com deficiência, pois, em suas palavras, "falta formação $e$ discussões a respeito de cada caso, também seria importante ter algum profissional de apoio, como psicólogo" (Questão 2). No entanto, lembra que possui informações adequadas sobre a inclusão de alunos com deficiência na escola, o que parece contraditório. Dentre as dificuldades enfrentadas pelos professores quando se trata da inclusão, Franciele acredita que "principalmente professores de área falta formação necessária para compreender cada particularidade de aluno (a)". (Questão 6). Franciele também diz: "acredito que mais formações 
na escola ou durante horário de trabalho, pois devido a grande carga de trabalho de alguns professores fica difícil buscar formação, além da questão financeira" (Questão 7).

Em relação à prática escolar inclusiva, o professor pode assumir o papel central no sentido de promover e estimular uma postura inclusiva entre seus estudantes (Questão 8). Essa foi uma das respostas da professora Franciele, quando refere: "acredito na inclusão, porém, penso que há ainda um longo caminho pela frente. O professor sim, ocupa este papel de promover e estimular, porém a escola como um todo deve ser participante deste processo"”.

Por sua vez, a professora Carol atua como professora de inclusão, tem trinta e dois (32) anos e possui o Ensino Médio de habilitação para o Magistério. Na resposta de Carol sobre estar preparada para atuar no atendimento ao aluno com deficiência e os conflitos que percebe para a produção do conhecimento em relação à inclusão (Questão 1), ela diz: "a área da inclusão é muito complexa, e no meu ver nunca estamos totalmente preparados para lidar com as questões que aparecem”. Carol afirma que as informações que têm sobre a inclusão de alunos com deficiência na escola é boa. Dentre as dificuldades enfrentadas pelos professores quando se trata da inclusão (Questão 2), Carol afirma "enquanto sala de recursos nossa maior dificuldade é a adaptação curricular e atividades planejadas pelo professor titularpara esses alunos" (Questão 6). Além disso, reforça que "é necessário que o professor busque capacitação especializada fora da escola através de cursos” (Questão 7), para fazer a inclusão de estudantes com múltiplas deficiências. Carol acredita na prática escolar inclusiva e na importância de o professor assumir o papel central, no sentido de promover e estimular uma postura inclusiva entre seus estudantes e diz: "sim, en acredito e é o professor que deve promover a postura inclusiva" (Questão 8).

A professora Cintia atua como professora de inclusão, tem 38 anos, possui ensino superior completo em Pedagogia e sua especialidade é no Atendimento Educacional Especializado. Ela afirma que está preparada para atuar no atendimento ao estudante com deficiência e que tem algumas dificuldades na elaboração do conhecimento em relação à inclusão das diferenças e deficiências na escola. Cintia responde "sim, sinto que estou preparada, a dificuldade maior é o atendimento dos alunos sem laudo médico, o que dificulta no planejamento de uma atividade específica” (Questão 1). Também afirma que a informação que tem sobre a inclusão dos alunos com deficiência é boa (Questão 2). Diante das principais dificuldades enfrentadas pelos professores quando 
se trata da inclusão (Questão 6), Cintia concorda com Carol dizendo "no nosso caso da sala de recursos, a maior dificuldade é a adaptação curricular e atividades que o professor titular não faz.para esses alunos". Cintia observa a necessidade de uma formação permanente nesse campo, afirmando: "é necessário que o profissional busque cursos de capacitação e formação para o atendimento especializado" (Questão 7). A professora acredita na prática escolar inclusiva e reafirma “sim, é o dever do professor promover a inclusão" (Questão 8).

A professora Débora, de 29 anos, atua na sala de recursos e sua formação é Pedagogia, com especialização em Inclusão Escolar, Gestão Escolar e Orientação Escolar. Em relação a sentir-se preparada para atuar no atendimento ao estudante com deficiência e seus conflitos (Questão 1), Débora diz: "em alguns momentos sinto-me preparada, mas em outros não, os conflitos são muitos, desde a falta de recursos e materiais até a pouca participação e falta de apoio das famílias e a falta de laudo. A escola e os professores fazem o possivel”. Das principais dificuldades enfrentadas quando se trata da inclusão (Questão 6), Débora tem os mesmos entendimentos que as professoras Cintia e Carol. A respeito da capacitação do professor para fazer a inclusão de estudantes com múltiplas deficiências (Questão 7), Débora defende que "é necessário que o professor busque capacitação fora da escola através de cursos, pois a rede municipal não oferece muitos cursos com essa temática". Débora acredita na prática escolar inclusiva, em suas palavras, "sim, eu acredito e é o professor que deve promover e estimular uma postura inclusiva" (Questão 8). Fica evidenciado que as professoras que trabalham com a inclusão constituem uma representação positiva da prática educativa e dos processos de convívio com os estudantes com alguma deficiência (SMEHA; FERREIRA, 2008).

Professora Fabiani tem 20 anos e possui o curso técnico de Magistério; sua área de atuação é a Inclusão. Ela não se sente preparada para atuar no atendimento ao estudante com deficiência (Questão 1), também afirma: "a falta de capacitação e preparação para os atendimentos são dificuldades comuns enfrentadas pelos professores quando se trata de inclusão" (Questão 6). A professora revela, quanto à forma de capacitação do professor e da escola para fazer a inclusão de estudantes com múltiplas deficiências, que precisa buscar isso fora da escola, pois a rede do município não oferece apoio (Questão 7). Também acredita na prática escolar inclusiva e afirma que precisa de apoio de estagiárias (Questão 8). Notamos que em resposta às questões 3, 4 e 5, as professoras expressaram posições praticamente iguais. Ambas registram que as turmas em que trabalham estão com 
número elevado de crianças e que há mais de 30 alunos deficientes na escola, com laudos e sem laudos, com múltiplas deficiências (Questão 3). A integração destes alunos é por meio da adaptação de carga horária reduzida quando necessário. Aos poucos, o educando é incluído na turma, com o auxílio do professor titular e do da sala de recursos (Questão 4). Quanto à participação da família do deficiente dentro da escola, algumas famílias participam quando são solicitadas, mas na grande maioria dos casos não se tem a participação familiar (Questão 5).

As respostas coletadas reforçam o que as autoras Smeha e Ferreira (2008, p. 37) identificaram em seus dados de pesquisa, apontando que "o sofrimento dos professores, diante do processo inclusivo, advém das dificuldades encontradas em suas práticas pedagógicas, pela falta de capacitação em sua formação acadêmica e carência de recursos disponibilizados pelas escolas para atender ao paradigma da educação inclusiva”. A garantia de formação, num curso de educação especial, não necessariamente cumpriria esse papel salvador diante das dificuldades práticas encontradas na realidade das escolas, de seus agentes, mas seria o primeiro passo para garantir os direitos à construção da identidade histórica das diferenças humanas, incluindo nesse contexto as deficiências e incapacidades mais severas. Frente ao exposto pelas professoras, identificamos inicialmente grandes entraves formativos, pois as cinco professoras em atuação, que responderam ao questionário, não têm o curso de graduação em Educação Especial. Carvalho, Habowski e Conte (2019, p. 172-173) afirmam que quando o professor que atua com deficientes possui "formação específica e permanente na área, ele consegue caminhar para formas experimentais e plurais de conhecer, colaborando com os educandos no desenvolvimento e estímulo do raciocínio e da possibilidade de transformação de saberes sensíveis aos contextos".

É perceptível nas respostas das professoras que, na rede regular de ensino, há uma tendência em garantir essa integração educacional por meio de serviços especializados; talvez por isso haja a dificuldade de incluir os estudantes no ensino regular, porque tal ensino continua sendo feito por segregação e motivado por laudos médicos. Não basta fazer uma integração postiça de sujeitos na escola com professores sem formação específica para acompanhar essas pessoas com deficiência; antes disso, é fundamental promover um processo de inclusão como projeto 
interdisciplinar, dada as condições das escolas públicas, para evitar a integração forçada e a exclusão.

Também identificamos algumas contradições nas respostas, pois embora as cincos professoras afirmem que não estão totalmente preparadas para lidar com esse tipo de atendimento, pois a inclusão é muito complexa, respondem à questão 2 dizendo que possuem a informação sobre a inclusão de alunos com deficiência. Tudo leva a crer que nunca estamos preparados totalmente para lidar com as questões que aparecem no trabalho com a deficiência, talvez também por falta de um planejamento com atividade interdisciplinares e ao mesmo tempo específicas para as variadas diferenças. Como vimos até aqui, são muitos os conflitos para dar conta das inteligências múltiplas, que vão desde a carência e defasagem formativa dos professores que atuam na área, passando pela ausência de apoio, materiais e recursos, e a pouca participação e incentivo das famílias.

Em geral, há barreiras conceituais diante do tema da inclusão e desafios práticos em relação às metodologias da educação inclusiva, às estratégias de referência, articulando experiência pedagógica e conhecimentos do DUA com as necessidades surgidas nessa relação educativa, inclusive por meio de colaboração, talvez devido ao pouco contato com as condições concretas das escolas regulares, e em pesquisas de campo. A insegurança, as tensões e o sentimento de despreparo dos professores para enfrentar os atravessamentos à educação inclusiva para todos leva à frustração pessoal e ao sentimento de impotência no campo da inclusão. O professor tem dificuldades para enfrentar estes sentimentos conflitantes, sente-se perdido e incapaz de repensar os conhecimentos pedagógicos para que se cumpra a função da garantia e direito à educação, para então formar cidadãos participantes e críticos do mundo social.

O fato é que a inclusão escolar vai além de ofertar acessibilidade estrutural aos estudantes com deficiências. "O grande problema na atualidade é que as escolas, além de não possuírem professores com especialização na área da educação inclusiva, também não estão preparadas para receber os estudantes com necessidades físicas especiais" ou com deficiências (MOURA; FREITAS, 2013, p. 45). A escola poderia também apresentar uma proposta de educação mais dinâmica e interdisciplinar para o desenvolvimento humano em suas múltiplas possibilidades e deficiências. Primeiramente, é fundamental acolher, acompanhar e atender cada estudante de perto, 
valorizando as suas próprias possibilidades e processos de construção individuais, em contato e interação com o coletivo, que também se desenvolve com a promoção da autoconfiança e da autoestima solidária da professora, em suas observações cotidianas, leituras e desafios lançados ao grupo de estudantes colaborativamente.

\section{Considerações finais}

Cabe lembrar que no Brasil encontramos inúmeras pesquisas sobre os cenários de Educação Inclusiva. Pletsch (2010) identificou em suas exaustivas investigações nesse campo que, embora tenhamos políticas e bases legais à educação inclusiva, ainda falta assegurar as condições mínimas para a realização de um trabalho pedagógico inclusivo e de formação pedagógica, sem simplificações ou posições dualistas que dividem e limitam professores e estudantes. Na verdade, o processo de formação de professores implica a construção de conhecimentos e competências que promovam as diferentes formas de pensar e agir dos sujeitos, mas que também revisem as diferenças que envolvem as práticas pedagógicas, ou seja, "o número excessivo de alunos nas salas de aula; os procedimentos inadequados de avaliação [...], a precária acessibilidade física de muitas escolas”, entre outros (PLETSCH, 2010, p. 87).

Para enfrentar os entraves da pouca formação dos professores observamos que é imprescindível, aos professores que atuam na área da educação especial, compreender as características e especificidades desse público-alvo à efetivação de processos, conhecimentos e competências para o desenvolvimento de ações inclusivas, vindo ao encontro das diferenças e peculiaridades de uma cultura inclusiva. A carência de uma identidade profissional e as condições incertas e conflitantes desse trabalho com a educação inclusiva se refletem no comportamento de isolamento do professor e de uma falta de legitimidade de sua prática na escola. Parece que o professor não pensa no processo inclusivo e apenas repete atividades de facilitação dos conteúdos escolares, colaborando na estigmatização das deficiências, seja por meio de laudos que atestam e apelam para o ensino compensatório/supletivo, seja por imposição de atividades que não dialogam com a turma em geral, acentuando ainda mais os contrastes e dualidades que envolvem a participação coletiva. Deste modo, concordamos com Ribeiro e Silva (2019, p. 2) quando afirmam que apesar dos 
avanços e das normativas que contemplam as diretrizes do conceito de educação inclusiva, "é necessário haver um questionamento sobre a efetividade das ações previstas para a educação especial e se estão em acordo com os preceitos estabelecidos acerca do que contempla uma educação de fato inclusiva".

A formação profissional abrange o estudo das exigências legais direcionadas a estes educandos, capacitando os mesmos para terem confiança em si para lidar com as diferenças e as inteligências múltiplas que acompanham os processos de ensino. A impossibilidade de oferecer experiências diversificadas e a falta de sensibilidade para incluir as diferenças no cotidiano escolar colocam em dúvida o ensino inclusivo e acarretam mais exclusão, superposição de ações ou uma falsa integração do que é a inclusão escolar e a participação de todos nas práticas educacionais. Para elucidar estas e outras questões, são abordadas teorias e práticas nas suas múltiplas expressões, aprendendo o campo inclusivo do direito de todos à educação, para uma sociedade que está em constante movimento, e isso envolve e requer a formação de professores e a renovação de práticas educativas, que reconhecem e incluem as diferenças nos espaços escolares.

Vale assinalar que não temos a intenção de desresponsabilizar o professor pelos processos de inclusão, no entanto, nas atuais condições da educação, o professor se encontra tão fragilizado e vulnerável na escola que sequer consegue acompanhar e desenvolver ações diversificadas para dar conta das diferenças, o que resulta no simples reforço às deficiências e às violências da exclusão presentes na escolarização. Fica em aberto a necessidade de pensar a inclusão educacional para dar conta da diversidade de sujeitos, mas sem apagar as singularidades, ou seja, como garantir o direito de uma educação inclusiva para incluir todos em sua globalidade e, ao mesmo tempo, respeitar a autenticidade humana.

\section{Referências}

ARAUJO, M. V.; RUSCHE, R. J.; MOLINA, R.; CARREIRO, L. R. R. Formação de professores e inclusão escolar de pessoas com deficiência: análise de resumos de artigos na base SciELO. Rev. psicopedag., São Paulo, v. 27, n. 84, p. 405-416, 2010.

BOCK, G.; GESSER, M.; NUERNBERG, A. O desenho universal para aprendizagem no acolhimento das expectativas de participantes de cursos de educação a distância. Revista Educação Especial, Santa Maria, v. 2019. https://doi.org/10.5902/1984686X34504 
BUENO, J. G. S. Educação especial brasileira: integração/segregação do aluno diferente. São Paulo: Editora da PUC/SP, 1993.

BRASIL. Ministério da Educação e Cultura. Lei no 9.394, de 20 de dezembro de 1996. Estabelece as diretrizes e bases da educação nacional. Brasília, 1996.

BRASIL. Ministério da Educação e Cultura. Secretaria de Educação Fundamental. Secretaria de Educação Especial. Parâmetros curriculares nacionais: Adaptações Curriculares. Brasília, 1998.

BRASIL. Ministério da Educação e Cultura. Resolução CNE/CEB N ${ }^{\circ}$ 2, de 11 de setembro de 2001. Institui Diretrizes Nacionais para a Educação Especial na Educação Básica. Brasília: MEC, 2001a.

BRASIL. Ministério da Educação e Cultura. Resolução CEB No 2, de 19 de abril de 1999. Institui Diretrizes Curriculares Nacionais para a Formação de Docentes da Educação Infantil e dos anos iniciais do Ensino Fundamental. Brasília, 1999.

BRASIL. Ministério da Educação e Cultura. Parecer CNE/CP no 9, de 8 de maio de 2001. Institui Diretrizes Curriculares Nacionais para a Formação de Professores da Educação Básica, em nível superior, curso de licenciatura, de graduação plena. Brasília, 2001b. (Instituída pela Resolução CNE/CP n ${ }^{\circ}$, de 18 de fevereiro de 2002).

BRASIL. Ministério da Educação e Cultura. Resolução CNE/CP n ${ }^{\circ}$ 1, de 15 de maio de 2006. Institui. Diretrizes Curriculares Nacionais para o Curso de Graduação em Pedagogia, licenciatura. Brasília, 2006.

BRASIL. Lei no 13.146, de 6 de julho de 2015. Lei Brasileira de Inclusão de Pessoas com deficiência. Brasília, 2015.

BRASIL. Secretaria de Educação Especial. Política Nacional de Educaşão Especial na Perspectiva da Educação Inclusiva. Legislação Específica. Documentos Internacionais, 2007.

BRASIL. Constituição de 1988. Constituição da República Federativa do Brasil. Brasília, DF: Senado Federal: Centro Gráfico, 1988.

BRASIL. Decreto $n^{\circ}$ 3.298, de 20 de dezembro de 1999. Regulamenta a Lei $n^{\circ} 7.853$, de 24 de outubro de 1989, dispõe sobre a Política Nacional para a Integração da Pessoa Portadora de Deficiência, consolida as normas de proteção, e dá outras providências. Diário Oficial da União, 21 dez. 1999. Seção 1, p. 10.

CAETANO, A. M.; PLETSCH, M. D. Os conceitos de inteligência e de deficiência intelectual: as mesmas origens? Revista Contrapontos, Itajaí, v. 19, n. 1, p. 392-407, jan./jun. 2019. https://doi.org/10.14210/contrapontos.v19n1.p392-407

CARVALHO, C. E. O.; HABOWSKI, A. C.; CONTE, E. A inclusão digital de crianças com múltiplas deficiências na escola. Revista Linhas, Florianópolis, v. 20, n. 42, p. 153-176, jan./abr. 2019. https://doi.org/10.5965/1984723820422019153

CARVALHO, R. C.; NAUJORKS, M. I. Representações sociais: dos modelos de deficiências a leitura de paradigmas educacionais. Revista Educação Especial, Santa Maria, n. 27, p. 1-8, 2006. Disponível em: http://periodicos.ufsm.br/educacaoespecial/article/view/4345/2555. Acesso em: 27 nov. 2019. 
CARVALHO, R. E. Removendo Barreiras para a Aprendizagem. Educação Inclusiva. Porto Alegre: Mediação, 2000.

CHARLOT, B. Da relação com o saber às práticas educativas. São Paulo: Cortez, 2014.

COSTA, V. A. Experiências pela educação: para quê? Formação e inclusão na perspectiva da teoria crítica. Revista Educaşão Especial, Santa Maria, v. 26, n. 46, p. 245-60, maio/ago. 2013. https://doi.org/10.5902/1984686X8029

FERREIRA, W. Inclusão X exclusão no Brasil: reflexões sobre a formação docente dez anos após Salamanca. In: RODRIGUES, D. (Org.). Inclusão e educação: doze olhares sobre a educação inclusiva. São Paulo: Summus, 2006.

FRANÇA, I. S. X.; PAGLIUCA, L. M. F.; BAPTISTA, R. S. Política de inclusão do portador de deficiência: possibilidades e limites. Acta Paulista de Enfermagem, v. 21, n. 1, p. 112-116, jan./mar. 2008. https://doi.org/10.1590/S0103-21002008000100018

GALEANO, E. De Pernas pro Ar: a escola do mundo ao avesso. Porto Alegre: L\&PM, 1999.

GIMENEZ, R. A inclusão de indivíduos portadores de necessidades especiais nas aulas regulares de educação física: repensando sobre a prática. Revista Digital, Buenos Aires, año 11, n. 98, jul. 2006. Disponível em: http://www.efdeportes.com/efd98/inclusao.htm. Acesso em: 17 nov. 2019.

GLAT, R.; FERNANDES, E. M. Da educação segregada à educação inclusiva: uma breve reflexão sobre os paradigmas educacionais no contexto da educação especial brasileira. Revista Inclusão, v. 1, n. 1, p. 35-39, 2005.

GONÇALVES, W.; GONÇALVES, V. M. F.; FIRME, L. P. Formação e capacitação de docentes para atuar com alunos com deficiência auditiva: um estudo no Instituto Federal do Espírito Santo - IFES. Ensaio: aval. pol. públ. Educ., Rio de Janeiro, v. 24, n. 93, p. 866-889, out./dez. 2016.

JAPIASSU, H. O Sonho Transdisciplinar. Desafios, v. 3, n. 1, p. 3-9, set. 2016.

LAMICHHANE, K.; SAWADA, Y. Disability and returns to education in a developing country. Economics of Education Review, v. 37, p. 85-94, 2013.

LIMA, P. A. Educação inclusiva e igualdade social. São Paulo: Avercamp, 2002.

MENDES, E. G. A política de educação inclusiva e o futuro das instituições especializadas no Brasil. Arquivos de análise de política de educaşão, v. 27, mar. 2019. https://doi.org/10.1590/S1413-65382011000400009

MENDES, R. H. (Org.). Educação inclusiva na prática: experiências que ilustram como podemos acolher todos e perseguir altas expectativas para cada um. São Paulo: Fundação Santillana, 2020.

MICHELS, M. H. (Org.). A Formação de Professores de Educação Especial no Brasil: propostas em questão. Florianópolis: UFSC/CED/NUP, 2017.

MINAYO, M. C. S. O desafio do conhecimento: pesquisa qualitativa em educação. São Paulo: Atlas, 1995. 
MITTLER, P. Educação Inclusiva: contextos sociais. 1. ed. Porto Alegre: Artmed, 2003.

MOSÉ, V. A escola e os desafios contemporâneos. Rio de Janeiro: Civilização Brasileira, 2013.

MOURA, M. M. G.; FREITAS, M. M. S. L. A Inclusão Escolar de Pessoas com Deficiência Física: aspectos jurídicos, teóricos e pedagógicos. Orientadora: Fátima de Nazaré Pantoja Rezende. Trabalho de Conclusão de Curso (Pedagogia) - Faculdades Integradas Ipiranga. Belém, Pará, 2013.

OLIVEIRA, E. S.; SILVA, T. P.; PADILHA, M. A. O.; BOMFIM, R. S. Inclusão Social: professores preparados ou não?. Polêm!ca, v. 11, n. 2, p. 314-323, maio 2012. https://doi.org/10.12957/polemica.2012.3103

PAGNI, P. A. Outros Olhares sobre a Inclusão Escolar. Rev. Bras. Ed. Esp., Marília, v. 23, n. 1, p. 161-162, jan./mar. 2017. https://doi.org/10.1590/S1413-65382317000100012

PERRENOUD, P. 10 novas competências para ensinar: convite à viagem. Porto Alegre: Artmed, 2000.

PLETSCH, M. D. Repensando a inclusão escolar: Diretrizes políticas, práticas curriculares e deficiência intelectual. Rio de Janeiro: Nau: Edur, 2010.

RIBEIRO, L. L.; SILVA, R. M. Educação especial nas políticas educacionais brasileiras: uma abordagem histórica. Arquivos de análise de política de educaşão, v. 27, mar. 2019. Disponível em: http://epaa.asu.edu/ojs/article/view/3073. Acesso em: 30 nov. 2019.

SANTOS, C. A. O Ano de 2020 e a educação no Brasil. Revista Sala de Recursos, v. 1, n. 1, p. 27-33, jan./abril 2021. Disponível em: http://www.saladerecursos.com.br. Acesso em: 17 ago. 2021 .

SIEMS, M. E. R. Educação especial em tempos de educação inclusiva: a identidade docente em questão. Linhas Críticas, Brasília, v. 14, n. 27, p. 209-226, jul./dez. 2008.

SMEHA, L. N.; FERREIRA, I. V. Prazer e sofrimento docente nos processos de inclusão escolar. Revista Educaşão Especial, Santa Maria, v. 1, n. 31, p. 37-48, 2008. Disponível em: http://periodicos.ufsm.br/educacaoespecial/article/view/8/20. Acesso em: 18 nov. 2019.

SVERDLICK, I. Inclusão educacional e o direito à educação: os sentidos em disputa. Arquivos de análise de política de educação, v. 27, n. 26, p. 1-25, mar. 2019. Disponível em: http://epaa.asu.edu/ojs/article/view/3197. Acesso em: 28 nov. 2019. 